\title{
Analysis of necking in tube hydroforming by means of extended forming limit stress diagram
}

\author{
R. Hashemi*
}

School of Mechanical Engineering, Iran University of Science and Technology, Tehran, Iran

\begin{tabular}{|c|c|}
\hline $\begin{array}{l}\text { A R T I C L E I N F O } \\
\end{array}$ & A B S T R A C T \\
\hline $\begin{array}{l}\text { Article history: } \\
\text { Received September 20, } 2013 \\
\text { Received in Revised form } \\
\text { October, } 14,2013 \\
\text { Accepted } 20 \text { February } 2014 \\
\text { Available online } \\
21 \text { February } 2014 \\
\text { Keywords: } \\
\text { Hydroforming } \\
\text { Simulation }\end{array}$ & $\begin{array}{l}\text { In this paper, an extended forming limit stress diagram (EFLSD) was applied to predict neck } \\
\text { initiation failure in tube hydroforming of metal bellows. The proposed EFLSD was used in } \\
\text { conjunction with ABAQUS/ EXPLICIT finite element simulations to predict the onset of } \\
\text { necking in tube hydroforming of metal bellows. The amount of calibration pressure and axial } \\
\text { feeding required to produce an acceptable part in finite element method (FEM) were compared } \\
\text { with the published experimental data and a satisfactory agreement between the FEM and } \\
\text { published test results was achieved. Therefore, the present approach can be used as a reliable } \\
\text { criterion for designing metal bellows hydroforming processes and reducing the number of } \\
\text { costly trials. }\end{array}$ \\
\hline
\end{tabular}

\section{Introduction}

Hydroforming is a fundamental forming process. This technique was developed at least six decades ago (Assempour et al., 2010). In recent years, there has been an accelerating growth in the production of hydro-formed products. Regarding process features and various blanks, hydroforming can be classified into sheet hydroforming and tube hydroforming (Lang et al., 2004; Hartl, 2005). In tube hydroforming, a relatively thin-walled tube is inflated by internal pressure and is forced to conform to the shape of the die which surrounds it (Korkolis and Kyriakides, 2008).

In the literature, there are several studies (Brunet et al., 2004; Jansson et al., 2008; Asnafi \& Skogsgardh, 2000) which investigated tubular hydroforming numerically and experimentally. However, failures such as buckling and necking which lead to burst of the tube could occur in the tube hydroforming process (Guan \& Pourboghrat, 2008; Kim et al., 2009). The causes of such defects

* Corresponding author.

E-mail addresses: rhashemi@iust.ac.ir (R. Hashemi) 
are mainly due to wrong loading conditions in applying the fluid pressure and axial feeding simultaneously (Faraji et al., 2010). Thus, it is important to conduct more research in this field (e.g., tube hydroforming process). Since bursting in tube hydroforming processes is the consequence of necking, the ability to predict necking is an important issue before designing the details of the processes. In the literature, there are some studies (e.g., Hashemi et al., 2009, 2010) which use a forming limit diagram in order to predict the initiation of necking in tube hydroforming. In most of these investigations the plane stress assumption has been applied. Allwood and Shouler (2009); Simha et al. (2007), Smith et al. (2003), Nurcheshmeh and Green (2012) showed necking in tube hydroforming could occur at locations where, in addition to the in-plane stresses, through thickness compressive stresses are also acted, and therefore the plane stress assumption is not appropriate for tube hydroforming especially for thicker parts. However, the aim of the present study is to present an example of using the previously developed model (Assempour et al., 2010) in metal bellows forming process. Another goal of this study is to demonstrate the ability of this model to predict the necking (failure) via finite element simulation.

The well-known M-K model (Marciniak \& Kuczynski, 1967) has been used in much theoretical and numerical sheet metal forming limit analyses. In this paper, an extended forming limit stress diagram (EFLSD) was applied to predict neck initiation failure in tube hydroforming of metal bellows. Determination of the EFLSD is based on the modified M-K model (Assempour et al., 2010). In addition, the proposed EFLSD have been used in conjunction with ABAQUS 6.5-1/ EXPLICIT finite element simulations to predict the onset of necking in tube hydroforming of metal bellows. The amount of calibration pressure and axial feeding required to produce an acceptable part in the finite element method (FEM) have been compared with the published experimental results.

\section{Summary of the EFLSD computation}

In this section, the modified M-K model (Assempour et al., 2009, 2010) has been reviewed. In this model, it has been assumed that there is a narrow groove in the surface. So, the tube material is composed of a safe area and a grooved area. This groove leads to localized necking in the tube material. Imposing of stress components at rolling and transverse directions in a safe area makes the progression of strain increments in both the safe and the groove areas (see Fig. 1). The computations in this paper are based on the work of Assempour et al. (2009). Hence, more explanations and details of method of the EFLSD computations can be found in Assempour et al. (2009).

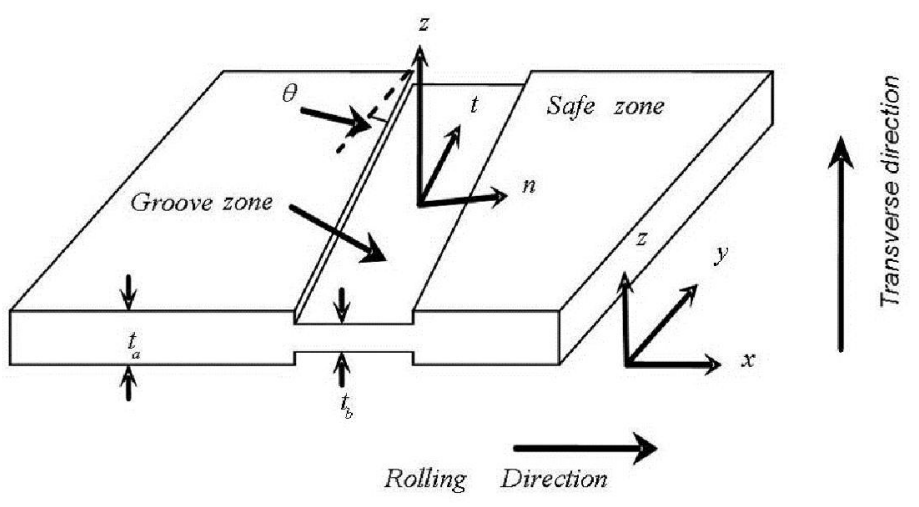

Fig. 1. The modified M-K model 


\section{Applied equations}

The general form of the yield criterion was used instead of the plane stress form to obtain the generalized FLDs in this work. Hill's (1948) yield function has been used to model the behavior of the tube material as follows:

$$
f(\sigma)=\sqrt{F\left(\sigma_{22}-\sigma_{33}\right)^{2}+G\left(\sigma_{33}-\sigma_{11}\right)^{2}+H\left(\sigma_{11}-\sigma_{22}\right)^{2}+2 L \sigma_{23}^{2}+2 M \sigma_{31}^{2}+2 N \sigma_{12}^{2}}
$$

where, $F, G, H, L, M$ and $N$ are the Hill's yield function coefficients.

$$
\begin{aligned}
& F=\frac{1}{2}\left(\frac{1}{R_{22}^{2}}+\frac{1}{R_{33}^{2}}-\frac{1}{R_{11}^{2}}\right), G=\frac{1}{2}\left(\frac{1}{R_{33}^{2}}+\frac{1}{R_{11}^{2}}-\frac{1}{R_{22}^{2}}\right), H=\frac{1}{2}\left(\frac{1}{R_{11}^{2}}+\frac{1}{R_{22}^{2}}-\frac{1}{R_{33}^{2}}\right) \\
& L=\frac{3}{2 R_{23}^{2}}, M=\frac{3}{2 R_{13}^{2}}, N=\frac{3}{2 R_{12}^{2}}
\end{aligned}
$$

These coefficients can be imported into the software by six yield stress parameters of $R_{11}, R_{22}$, $R_{33}, R_{12}, R_{13}$ and $R_{23}$. These parameters can be computed using anisotropic parameters of $r_{0}, r_{45}$ and $r_{90}\left(r_{0}=r_{x}\right.$ and $\left.r_{90}=r_{y}\right)$ as follows,

$$
R_{11}=R_{13}=R_{23}=1, R_{22}=\sqrt{\frac{r_{y}\left(r_{x}+1\right)}{r_{x}\left(r_{y}+1\right)}}, R_{33}=\sqrt{\frac{r_{y}\left(r_{x}+1\right)}{\left(r_{x}+r_{y}\right)}}, R_{12}=\sqrt{\frac{3\left(r_{x}+1\right) r_{y}}{\left(2 r_{45}+1\right)\left(r_{x}+r_{y}\right)}}
$$

In this study, the power law is used to describe the effective stress $\bar{\sigma}_{Y}$ as a function of effective strain $\bar{\varepsilon}$, strain hardening exponent $n$, and strength coefficient $K$. This relation is defined as follows,

$\bar{\sigma}_{Y}=K(\bar{\varepsilon})^{n}$

Furthermore, to determine an extended forming limit stress diagram, which was characterized by the two invariants, mean stress and equivalent stress the Eq. (1) and the following relation for mean stress is needed.

$$
\sigma_{\text {Hydro }}=\frac{\sigma_{1}+\sigma_{2}+\sigma_{3}}{3}
$$

\section{FE modeling}

The bellows had ten rings, and the material was Phosphor Bronze CuSn6. Initial tube dimensions and material properties could be found in Table 1. The ABAQUS 6.5-1 Explicit commercial finite element code was used to simulate the forming process of the metal bellows. Elastic-plastic numerical formulation was used in FEM. Due to the symmetry, only one ring of the bellows was simulated. Totally 56 RAX2 axisymmetric type elements were used to mesh one ring of the bellows. Fig. 2 shows deformable tube and annular rigid plate die. Dimensions and mechanical properties are shown in Fig. 2 and Table 1, in which $r_{0}$ and $t_{0}$ are the initial radius, thickness of the tube, $D_{c}$ is the Die stroke (the initial distance between the plate die) and $d$ is the plate dies thickness. The fillet radius is $0.5 \mathrm{~mm}$. The coefficient of friction is $0.1 \mathrm{in} \mathrm{FEM}$. 
In this study, based on (Faraji et al., 2008, 2010; Hashemi et al., 2010) the metal bellows was formed in two stages (bulging and folding) from seamless full annealed tube. Loading conditions (axial displacement and internal pressure) are shown in Fig. 3. In bulging and folding processes, the tube was constrained by some equally spaced annular plate dies. In the bulging step, internal pressure was increased linearly with time and no axial displacement was applied ( $0-0.005 \mathrm{~s}$ in Fig. 3$)$. In the folding step, axial feeding was applied to the end of the tube, while internal pressure remained constant $(0.005-0.01 \mathrm{~s}$ in Fig. 3). During bulging, the length of the tube was constant, and no axial displacement was applied. As soon as the internal pressure reached its maximum value at the end of the bulging step, folding stage was started, and displacement was applied to the end of the tube and internal pressure remained constant.

The present metal bellows FE model for Phosphor Bronze CuSn6 was verified. The results are shown in Fig. 4. This Figure illustrates the effect of internal pressure on the thickness distribution in the bellows forming process. Increase in internal pressure leads to excessive thinning (Faraji et al., 2008). As the results illustrate; good agreement with experimental data was achieved for this material (e.g., Table 2). From Table 2 comparison between the results of two methods shows $4 \%$ difference that is a quite good consistency.

Table 1

Mechanical properties and dimension of the initial tubes (Metal bellows) (Faraji et al., 2008)

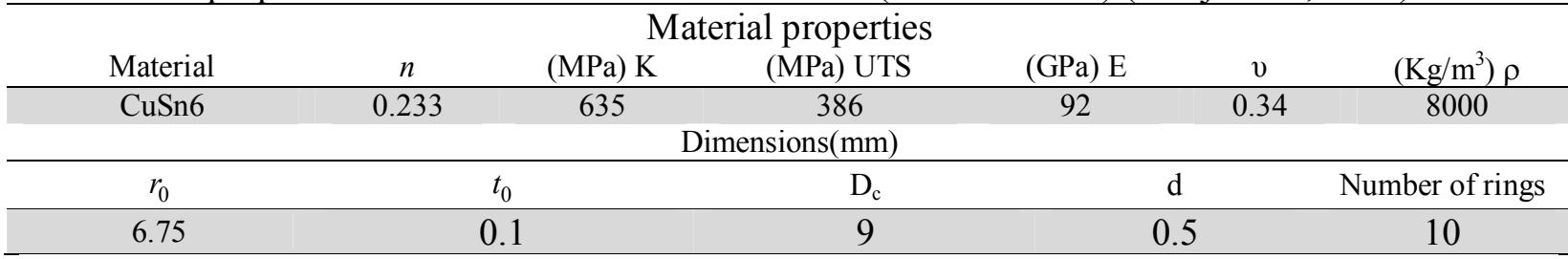

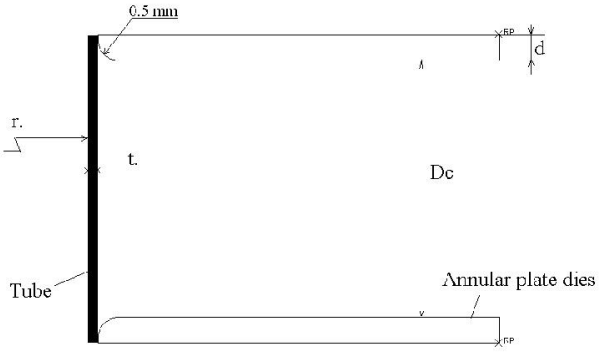

Fig. 2. Model of one ring of the metal bellows

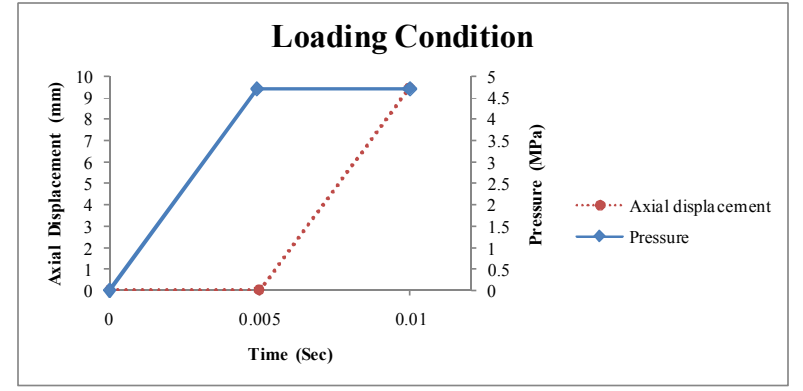

Fig. 3. Loading conditions for experiments (Faraji et al., 2008) and FEM

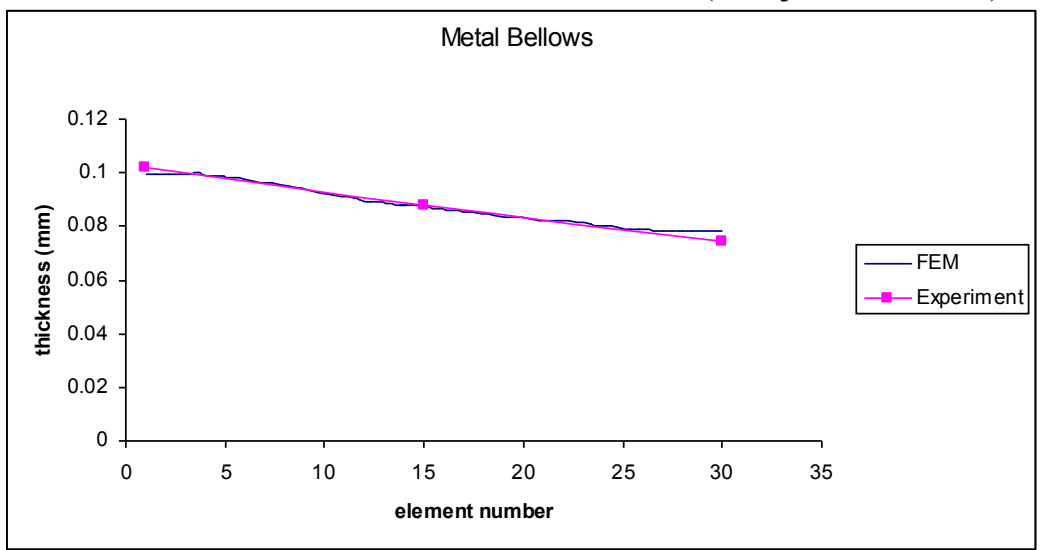

Fig. 4. Thickness distribution of the bellows (die stroke and feeding are constant) 
Table 2

Comparison between the minimum thicknesses resulted from FEM and experiment (Metal bellows)

Minimum thickness (mm)

FEM 0.078

Experiment (Faraji et al., 2008) 0.075

\section{Review of Experiment}

The die stroke in experiment was $10 \mathrm{~mm}$, feeding 95\% and internal pressure 4.5 $\mathrm{MPa}$. The pressure was produced by a gear type pump, in which there was considerable fluctuation in pressure. Because of the sensitivity of the process to variation of internal pressure, using a system to eliminate these fluctuations was necessary. The fluid used in the experiment was a kind of mineral oil and one of the problems in the experiment was to seal the ends of the tube because the tube thickness was so thin. The annular plate die material was AISI420 stainless steel that was hardened to 45 HRC. Detailed descriptions about experiment of metal bellows manufacturing can be found in (Faraji et al., 2008).

Fig. 4 shows the thickness variation of manufactured bellows from CuSn6 and element numbers of FEM model. In this case, thickness was measured using an optical microscope with magnification of 100. The minimum thickness measured in the experiment was $0.075 \mathrm{~mm}$ (Fig. 4). In measuring the thickness distribution of the work-piece, conventional measuring instruments could not be used because of small dimensions and complicated geometry of the bellows section (Faraji et al., 2008). Therefore, in measuring the thickness distribution of the work-piece, at first the bellows were separated into two halves by wire electro-discharge machining (EDM) cutting machine in the diametrical direction and then they were polished to remove the roughness of the work-piece.

\section{Results and discussions}

It should be mentioned that, due to the non-proportional nature of loading associated with the tube hydroforming process, the strain paths of the deformation are also non-linear in nature. Thus the FLD of tube material, obtained by a series of proportional loadings, is not valid for this tube hydroforming process (Hashemi et al., 2009). However, many researchers (Brunet et al., 2004; Kim et al., 2009) have nevertheless used the as-received FLD to predict necking initiation in tube hydroforming processes. Moreover, the FLD gives an approximate estimation of the possible bursting zones. Recently, Simha et al. (2007) developed an extended stress-based forming limit diagram (EFLSD) that could be used to predict the onset of necking in sheet metal loaded under nonproportional load paths, as well as under three-dimensional stress states. The conventional strainbased FLD was transformed into the stress-based FLD. This, in turn, was converted into the EFLSD, which was characterized by the two invariants, mean stress and equivalent stress. The FLD and EFLSD were used in conjunction with FE computations to predict the onset of necking during tubular hydroforming.

Thus, to analyze the risk of bursting, the FLD and also the corresponding extended forming limit stress diagram were computed and used in this work. The extended stress-based forming limit diagram and effective stress and mean stress values extracted from FEM for bellows that modeled for an internal pressure $4.65 \mathrm{MPa}$ and a die stroke equal to $10 \mathrm{~mm}$ have been shown in Fig. 5. This Figure shows that the resulted stress values from FEM are in the safe area.

The EFLD and effective stress and mean stress values extracted from FEM for bellows modeled with an internal pressure $4.8 \mathrm{MPa}$ and a die stroke equal to $10 \mathrm{~mm}$ have been shown in Fig. 6 . This figure shows that some of the resulted stress values from FEM are not in the safe area and failure may occur. In the literature, there are some researchers (e.g., Hashemi et al., 2009, 2010) who assumed 
plane stress conditions in order to obtain the FLDs for their tube hydroforming process. But as mentioned above, the compressive normal stress shifts the FLD up (e.g., it has an effect on the FLD) (Assempour et al., 2010), especially when the material thickness is significant. The greatest difficulty to obtain the FLD with the M-K method is the requirement of some experimental results other than usual material properties. In the case of $\mathrm{M}-\mathrm{K}$ model, requirement is least, and only one point of experimental FLD (usually $\mathrm{FLD}_{0}{ }^{1}$ ) is needed to find the initial in-homogeneity coefficient, $\mathrm{f}_{0}$, and calibrate the diagram (Ghazanfari \& Assempour, 2012). As reported in the literature (e.g., Ghazanfari \& Assempour, 2012; Hashemi et al., 2012), sensitivity of the diagram to variations of $\mathrm{f}_{0}$ is very high, and if it is presumed inaccurately, the resulting FLD will differ greatly from the experimental data.

Some investigations have been done to reduce the requirement of experimental data in determining the FLD. These investigations fall into four main categories:

1- Using empirical laws: these methods are very practical and useful in industrial applications because of their simplicity and requirement of few parameters. However, these laws have limitations and are suitable only for a certain groups of materials. Perhaps the most renowned relation is the one proposed by Keeler and Brazier (Ghazanfari \& Assempour, 2012) and known as NADDRG ${ }^{2}$ relation in the literature. This empirical law is suitable for low carbon steels. The value of $\mathrm{FLD}_{0}$ in terms of engineering strain is obtained from Eq. (6) (Ghazanfari \& Assempour, 2012):

$$
F L D_{0}=(23.3+14.13 t(m m))(n / 0.21)
$$

2- Using grain size and surface roughness: another method for obtaining the FLD is to relate the grain size and surface roughness of the sheet metal to geometrical in-homogeneity. An example of such relations is presented in Eq. (7) (Gronostajski \& Zimniak, 1992):

$f_{0}=\frac{t_{0}^{a}-2\left(R+K d_{0}^{0.5} \bar{\varepsilon}^{b}\right)}{t_{0}^{a}}$,

where $R$ is the initial surface roughness, $d_{0}$ is the grain size and $K$ is a material constant. The predicted FLDs show good agreement with experimental results but require of many experimental constants which are difficult and time-consuming to determine. Therefore, this method is less popular.

3- Using strain gradient theory (Safikhani et al., 2008, 2009): in this method the strain gradient theory of plasticity is incorporated into the $\mathrm{M}-\mathrm{K}$ method to compute the FLD. It has been shown that variations of the initial in-homogeneity factor have a negligible effect on the FLD. On the other hand, mathematical complexity and some required experimental parameters have also affected the popularity of this method.

4- To benefit from the advantage of assuming material in-homogeneity rather than geometrical inhomogeneity, it has been tried (Ghazanfari \& Assempour, 2012) to find an empirical law to predict the value of $\mathrm{N}$ for different materials (the in-homogeneity as ratio of the strain hardening exponent of zone "b" to that of region "a" (i.e. $\left.N=n^{b} / n^{a}\right)$ ). It could have been tried to find an empirical law for $\mathrm{f}_{0}$, but a small error in the determination of $\mathrm{f}_{0}$ would result in a large error in predicted FLD, whereas using the empirical law for "N" will result in FLDs which are in good agreement with experimental diagrams (Ghazanfari \& Assempour, 2012).

\footnotetext{
${ }^{1} \mathrm{FLD}_{0}$ is the major strain in plane strain state that results in necking.

${ }^{2}$ North American Deep Drawing Research Group
} 
To derive the empirical law (Ghazanfari \& Assempour, 2012), a large number of experimental data for different materials used in forming processes were collected from the literature and the appropriate values of $\mathrm{N}$ were determined for each of them by trial and error. Surprisingly the value of "N" is only a function of material thickness and the same law applies for different types of materials. To obtain the most appropriate relation, various curves were fitted to the diagram of $\mathrm{N}$ vs. $\mathrm{t}$, and the best results were obtained with the following equation (Ghazanfari \& Assempour, 2012):

$\mathrm{N}=1+0.0292 \exp (-2.02 \times \mathrm{t}(\mathrm{mm})+0.7466)$

The success and accuracy of this law to predict the initial in-homogeneity and its advantages over other methods have been discussed in reference (Ghazanfari and Assempour, 2012). It seems that this empirical law can be applied to all materials and there is no need to do significant experimental work to determine this empirical law for each tube material under consideration. Thus, this method uses only tube material thickness to calculate " $N "$.

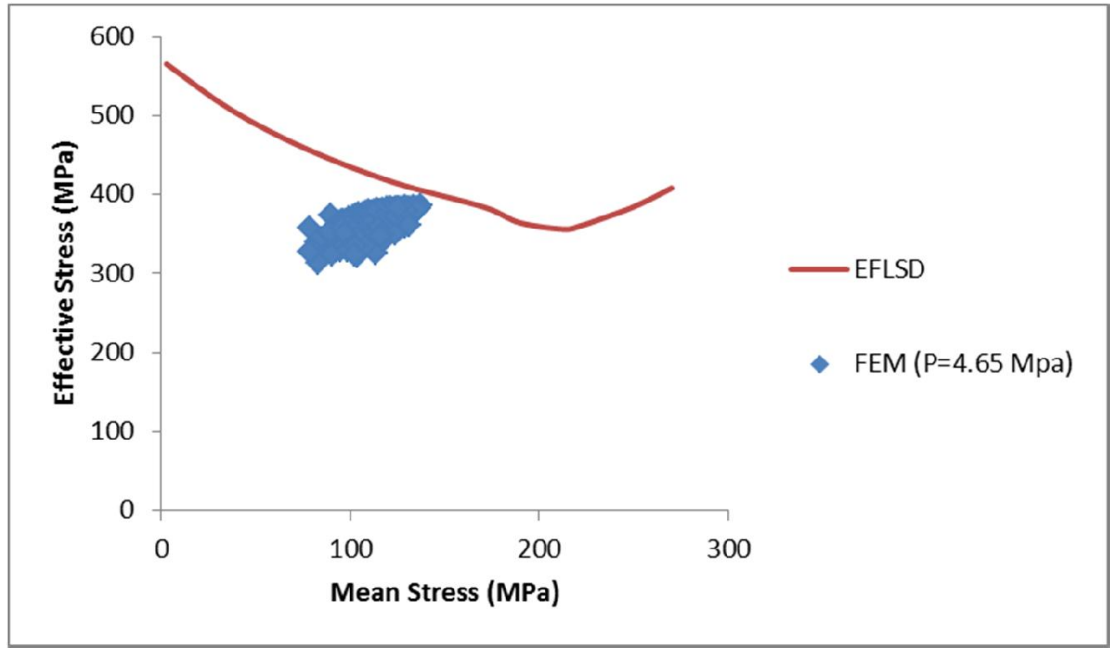

Fig. 5. Extended stress-based FLD and effective stress and mean stress values extracted from FEM for acceptable bellows (assuming $\mathrm{N}=1+0.0292 \exp (-2.02 \times 0.1(\mathrm{~mm})+0.7466)=1.05034$ and material: Phosphor Bronze CuSn6)

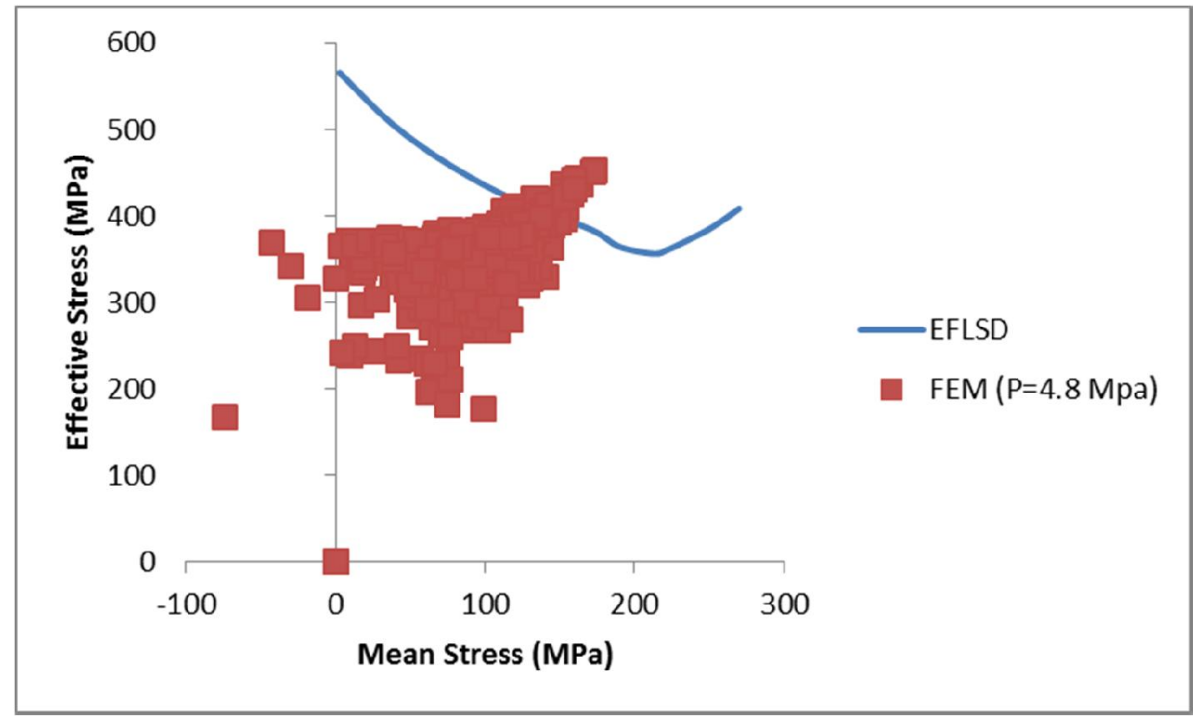

Fig. 6. Extended stress-based FLD and effective stress and mean stress values extracted from FEM (assuming material in-homogeneity coefficient $\mathrm{N}=1+0.0292 \exp (-2.02 \times 0.1(\mathrm{~mm})+0.7466)=1.05034$ and material: Phosphor Bronze CuSn6) 


\section{Conclusions}

In the present study, the modified M-K model was used to obtain the FLDs and the extended stress-based FLDs. The FLD concept allows a correct analysis on the material formability, while the EFLSD concept means a good stop test on the applications involving non-proportional loadings. Therefore, a combination of the FLD and EFLSD can be used as a perfect method in order to examine tube hydroforming process. By using the present methodology for the prediction of the FLD and EFLSD in the CAD/FEM, it may be possible to optimize the design of the tube hydroforming process much quicker and to eliminate expensive and time consuming trial-and-error techniques.

\section{Acknowledgement}

The author would like to acknowledge the financial support of Iran National Science Foundation (INSF).

\section{References}

Allwood, J. M., \& Shouler, D. R. (2009). Generalised forming limit diagrams showing increased forming limits with non-planar stress states. International Journal of Plasticity, 25(7), 1207-1230.

Asnafi, N., \& Skogsgårdh, A. (2000). Theoretical and experimental analysis of stroke-controlled tube hydroforming. Materials Science and Engineering: A, 279(1), 95-110.

Assempour, A., Hashemi, R., Abrinia, K., Ganjiani, M., \& Masoumi, E. (2009). A methodology for prediction of forming limit stress diagrams considering the strain path effect. Computational Materials Science, 45(2), 195-204.

Assempour, A., Nejadkhaki, H. K., \& Hashemi, R. (2010). Forming limit diagrams with the existence of through-thickness normal stress. Computational Materials Science, 48(3), 504-508.

Assempour, A., Safikhani, A. R., \& Hashemi, R. (2009). An improved strain gradient approach for determination of deformation localization and forming limit diagrams. Journal of Materials Processing Technology, 209(4), 1758-1769.

Brunet, M., Boumaiza, S., \& Nefussi, G. (2004). Unified failure analysis for tubular hydroforming. Journal of materials processing technology, 148(2), 269-277.

Faraji, G., Hashemi, R., Mashhadi, M. M., Dizaji, A. F., \& Norouzifard, V. (2010). Hydroforming Limits in Metal Bellows Forming Process. Materials and Manufacturing Processes, 25(12), 14131417.

Faraji, G., Besharati, M. K., Mosavi, M., \& Kashanizadeh, H. (2008). Experimental and finite element analysis of parameters in manufacturing of metal bellows. The International Journal of Advanced Manufacturing Technology,38(7-8), 641-648.

Ghazanfari, A., \& Assempour, A. (2012). Calibration of forming limit diagrams using a modified Marciniak-Kuczynski model and an empirical law. Materials \& Design, 34, 185-191.

Gronostajski, J. Z., \& Zimniak, Z. (1992). The effect of changing of heterogeneity with strain on the forming limit diagram. Journal of Materials Processing Technology, 34(1), 457-464.

Guan, Y., \& Pourboghrat, F. (2008). Fourier series based finite element analysis of tube hydroforming - generalized plane strain model. Journal of Materials Processing Technology, 197(1), 379-392.

Hartl, C. (2005). Research and advances in fundamentals and industrial applications of hydroforming. Journal of Materials Processing Technology, 167(2), 383-392.

Hashemi, R., Assempour, A., \& Abad, E. M. K. (2009). Implementation of the forming limit stress diagram to obtain suitable load path in tube hydroforming considering $\mathrm{M}-\mathrm{K}$ model. Materials \& Design, 30(9), 3545-3553.

Hashemi, R., Faraji, G., Abrinia, K., \& Dizaji, A. F. (2010). Application of the hydroforming strainand stress-limit diagrams to predict necking in metal bellows forming process. The International Journal of Advanced Manufacturing Technology, 46(5-8), 551-561. 
Hashemi, R., Ghazanfari, A., Abrinia, K., \& Assempour, A. (2012). Forming limit diagrams of ground St14 steel sheets with different thicknesses. SAE International Journal of Materials \& Manufacturing, 5(1), 60-64.

Hill, R. (1948). A theory of the yielding and plastic flow of anisotropic metals. Proceedings of the Royal Society of London. Series A. Mathematical and Physical Sciences, 193(1033), 281-297.

Hashemi, R., Abrinia, K., \& Assempour, A. (2012). The strain gradient approach to predict necking in tube hydroforming. Journal of Manufacturing Processes.

HARI MANOJ SIMHA, C., Gholipour, J., Bardelcik, A., \& Worswick, M. J. (2007). Prediction of necking in tubular hydroforming using an extended stress-based forming limit curve. Journal of engineering materials and technology, 129(1), 36-47.

Korkolis, Y. P., \& Kyriakides, S. (2008). Inflation and burst of anisotropic aluminum tubes for hydroforming applications. International Journal of Plasticity, 24(3), 509-543.

Jansson, M., Nilsson, L., \& Simonsson, K. (2008). On strain localisation in tube hydroforming of aluminium extrusions. Journal of materials processing technology, 195(1), 3-14.

Kim, J., Song, W. J., \& Kang, B. S. (2009). Probabilistic modeling of stress-based FLD in tube hydroforming process. Journal of mechanical science and technology, 23(11), 2891-2902.

Lang, L. H., Wang, Z. R., Kang, D. C., Yuan, S. J., Zhang, S. H., Danckert, J., \& Nielsen, K. B. (2004). Hydroforming highlights: sheet hydroforming and tube hydroforming. Journal of Materials Processing Technology, 151(1), 165-177.

Marciniak, Z., \& Kuczyński, K. (1967). Limit strains in the processes of stretch-forming sheet metal. International Journal of Mechanical Sciences, 9(9), 609-620.

Nurcheshmeh, M., \& Green, D. E. (2012). Influence of out-of-plane compression stress on limit strains in sheet metals. International journal of material forming, 5(3), 213-226.

Smith, L. M., Averill, R. C., Lucas, J. P., Stoughton, T. B., \& Matin, P. H. (2003). Influence of transverse normal stress on sheet metal formability. International Journal of Plasticity, 19(10), 1567-1583.

Safikhani, A. R., Hashemi, R., \& Assempour, A. (2008). The strain gradient approach for determination of forming limit stress and strain diagrams.Proceedings of the Institution of Mechanical Engineers, Part B: Journal of Engineering Manufacture, 222(4), 467-483.

Safikhani, A. R., Hashemi, R., \& Assempour, A. (2009). Some numerical aspects of necking solution in prediction of sheet metal forming limits by strain gradient plasticity. Materials \& Design, 30(3), 727-740. 


$\begin{array}{ll}\text { Appendix I: Notation } & \\ E & \text { Young's elastic modulus } \\ f & \text { Imperfection factor } \\ F, G, H, L, M, N & \text { Hill's yield function coefficients } \\ K, n, m, \bar{\varepsilon}_{0} & \text { Material constants } \\ r & \text { Average anisotropic parameter } \\ r_{0}, r_{45}, r_{90} & \text { Ratios of transverse to through-thickness strains under uniaxial } \\ t & \text { tension at } 0,45 \text { and } 90^{\circ} \text { to the rolling direction } \\ \sigma_{1}, \sigma_{2} & \text { Material thickness } \\ \sigma_{x x}, \sigma_{y y}, \sigma_{x y} & \text { Stress components in the material coordinates } \\ \sigma_{n n}, \sigma_{n t}, \sigma_{t t} & \text { Planer components of stress tensor in the orthotropic referential } \\ \bar{\sigma}_{Y} & \text { frame } \\ \bar{\sigma}_{y} & \text { Stress components in the groove coordinates in the state of } \\ \dot{\bar{\varepsilon}} & \text { plane stress } \\ \bar{\varepsilon} & \text { Effective stress obtained from hardening law } \\ d \bar{\varepsilon} & \text { Effective stress obtained from yield function } \\ d \varepsilon_{1}, d \varepsilon_{2}, d \varepsilon_{3} & \text { Rate of effective plastic strain } \\ d \varepsilon_{t t}, d \varepsilon_{n n}, d \varepsilon_{n t} & \text { Effective plastic strain } \\ d \varepsilon & \text { Effective plastic strain increment } \\ v & \text { Strain increments in the material coordinates } \\ \alpha & \text { Strain increments in the groove coordinates } \\ \rho & \text { Strain increments tensor } \\ \theta & \text { Poission's ratio } \\ & \text { Ratio of stresses along the strain path } \\ & \text { Ratio of strain increments along the strain path } \\ & \text { Groove angle between the groove coordinates and the material } \\ & \text { coordinates }\end{array}$

